\title{
Investigation of Electrohydraulic Control of A Gas Turbine Engine's Inlet Guide Vanes
}

\author{
$\{$ Mostafa M. Samy, Mohamed A. Metwally, Wael M. Elmayyah, Ibrahem A. Elsherif\}
}

\begin{abstract}
Electrohydraulic systems play a pivotal role in controlling gas turbine engines. One of the most challenging problems in electrohydraulic control systems is modeling the nonlinearity of fluid behavior due to special shaped orifices. Previous published studies have not treated modeling of such hydraulic systems in much detail, although they are widely used in aircraft engines and ground vehicles equipped with gas turbine engines. Presenting a validated model for an electrohydraulic position control system is fundamental to design and compare the effect of different control techniques on the system behavior.
\end{abstract}

In this paper, a detailed study of a fuel based electrohydraulic position control system was presented. This system is used in an air gas turbine engine of a ground equipment. The system controls the engine's air inlet guide vanes (IGV) position by means of linear hydraulic actuator. This actuator, in turn, is controlled via contactless electrohydraulic servo solenoid valve. A test rig was built to expedite measuring the actual system response and controlling it. A mathematical dynamic model was derived and solved using SIMULINK, a Matlab® application. Predicted results were compared with the experimental measured results. The comparison showed that the most extreme difference between the measured and predicted results was less than 5\%. Therefore, the presented model could be used to design and compare the effect of different control techniques on the system behavior for further development.

\section{Introduction}

Electrohydraulic control valves are widely used in many of hydraulic position control applications [1-6]. In order to study, design and control such systems modeling of them is strongly needed. Many approaches have been taken into consideration to model the electrohydraulic control systems [2,7-11]. In this study, a full dynamic model approach will be taken into consideration to model the system. In order to validate the model, it will be compared with the real system behavior. The specific objective of this study is to investigate the electrohydraulic control of a gas turbine engine's IGV on order to build a dependable mathematical model to predict the system behavior.

\section{System Description}

The system under study is part of the fuel management and control system of a gas turbine engine of a ground equipment. In this study, our interest is the Electro Hydraulic Servo Actuator system (EHSA) which accurately controls the IGV of the engine. 
Figure (1) shows the functional scheme of the studied EHSA. The system derived by vane pump (1) runs on diesel fuel. The pressurized fuel is pumped into a zero-lapping servo solenoid directional control valve (4). The valve's spool (5) movement controls the direction and the flow rate comes out from the valve to the actuator (11). The spool movement governed by a stroke controlled proportional solenoid (3) in contactless manner.

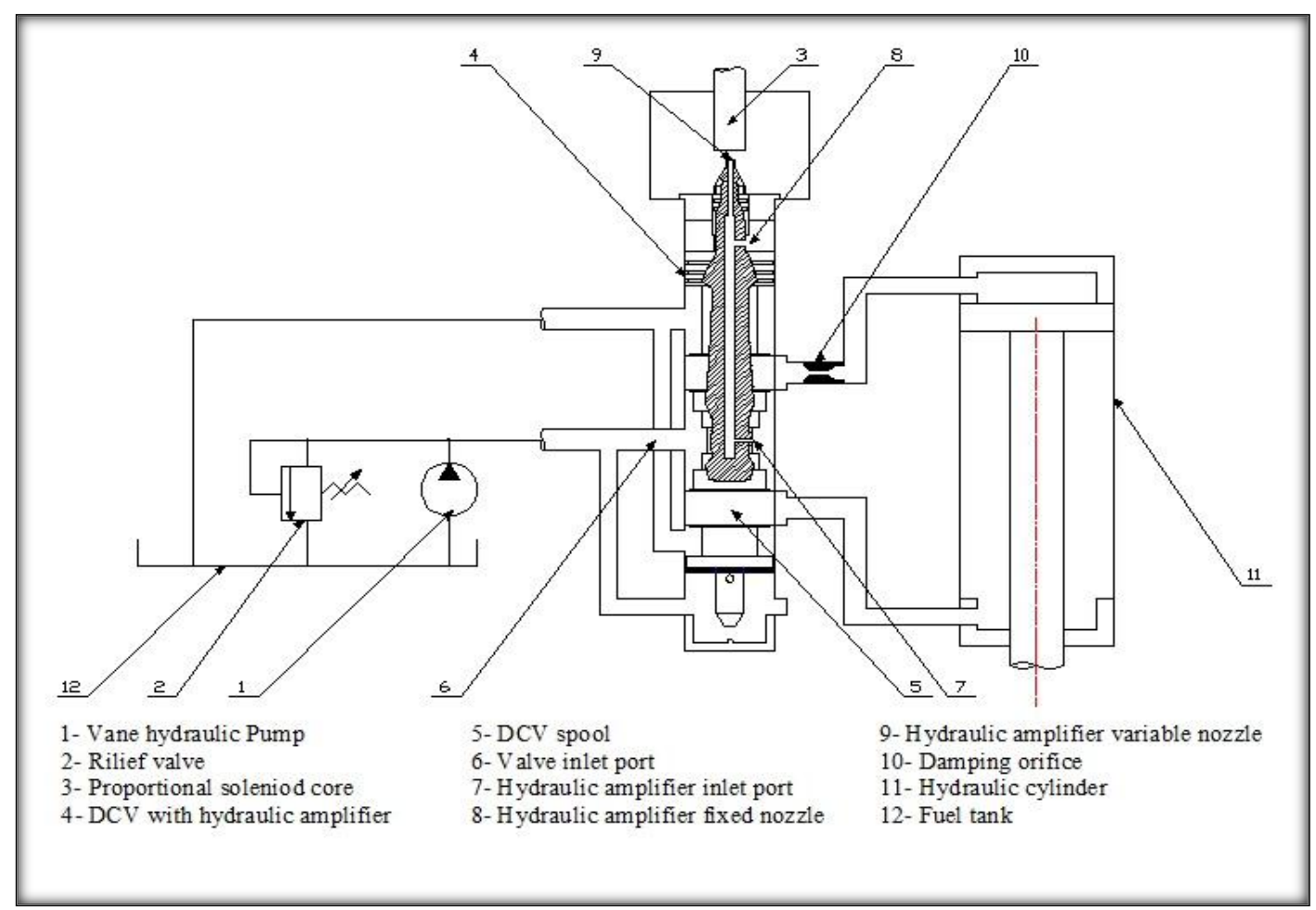

Fig. (1) Scheme of the studied EHSA

The spool incorporates a hydraulic amplifier (7) controlled by the width of the gab separating the amplifier nozzle (9) and the solenoid core (3). The hydraulic amplifier serves to convert the small solenoid core displacement into a considerable pressure force. This force pilot controls the spool movement.

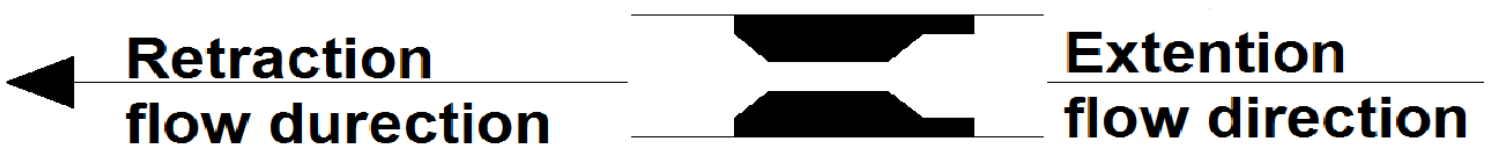

Fig. (2) Short tube orifice

In order to insure the required damping, in both directions, of the piston's motion an additional orifice (10) is added in the connecting line to the actuator's cap side. Figure (2) illustrates the shape of this orifice which consists of convergent, short tube, divergent orifices. This orifice will be mentioned as the short tube orifice from now on in this article for simplification. The piston's rod displacement is measured using rotary variable differential transformer (RVDT). RVDT connected by a frictionless wire and a small rotating cam to the rod tip. 


\section{Dynamic Model}

In this section, the governing equations for the dynamic model of the system described above will be derived. The dynamic model will be divided into three main sections; electromagnetic solenoid, hydraulic valve, and actuator.

\subsection{Electromagnetic Solenoid}

The proportional solenoid depicted in Fig. (3) is a linear traverse and limited travel DC solenoid. It can be represented as a linear inductor $(\mathrm{L})$ with a resistor in series $(\mathrm{R})$. The electric parameters of the solenoid coil were measured on zero frequency. Coil resistor is $(\mathrm{R}=10 \Omega)$ and inductance is $(\mathrm{L}=27.8 \mathrm{mH})$. The voltage/current relationship can be derived by equation (1). For small displacement, the inductance rate of change is tiny so it can be neglected as in equation (2).

$$
\begin{gathered}
V_{i}=V_{R}+V_{L}=i R+L \frac{d i}{d t}+i \frac{d L}{d t} \\
V_{i}=i R+L \frac{d i}{d t}
\end{gathered}
$$

The current force relationship mentioned in [8] can be described as a linear equation between the magnetic force effects the solenoid core and the current passes through its coil. The proportionality factor $\left(\mathrm{k}_{\mathrm{si}}\right)$ is the current-force gain, N/A.

$$
\boldsymbol{F}_{M}=\boldsymbol{k}_{s i} * \boldsymbol{i}
$$

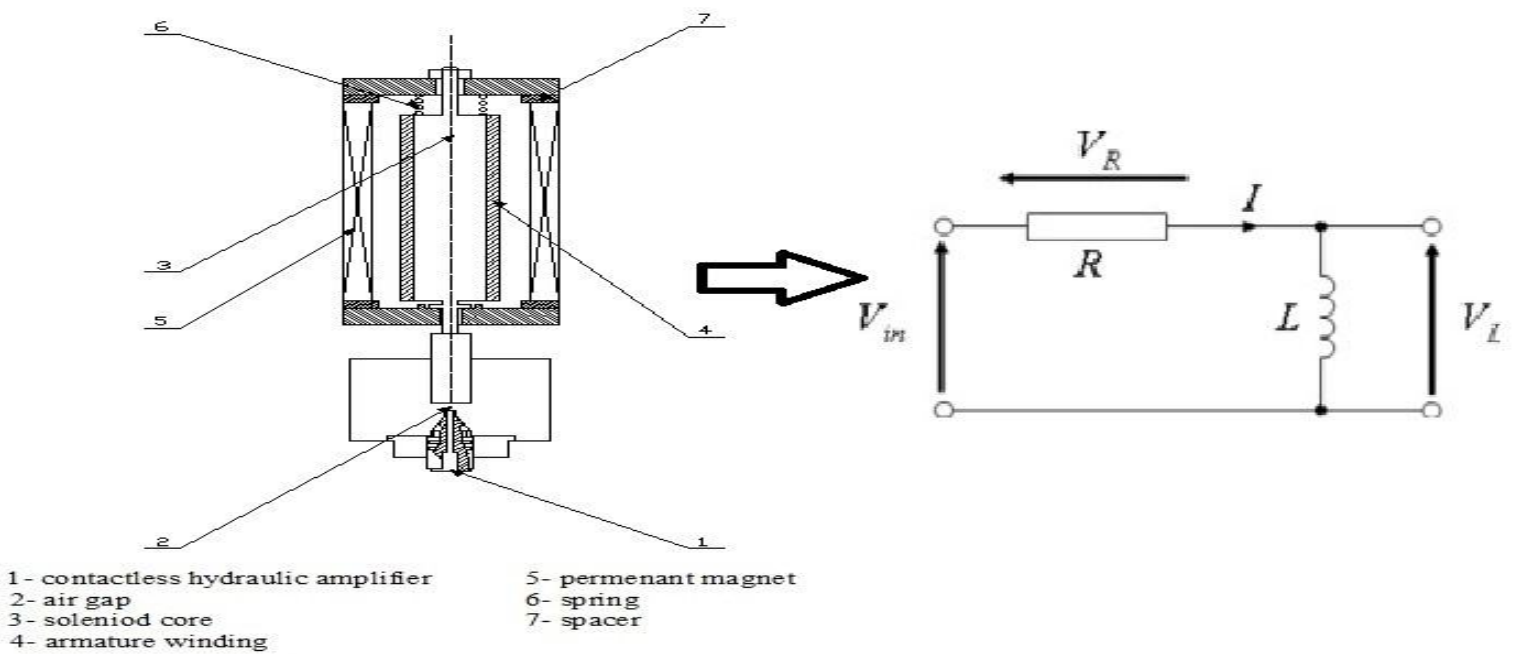

Fig. (3) Proportional solenoid

In other hand equation of motion of the solenoid can be described according to Newton's $2^{\text {nd }}$ law in equation

$$
\boldsymbol{m}_{c} \boldsymbol{x}_{\boldsymbol{c}}^{\prime \prime}=\boldsymbol{F}_{\boldsymbol{M}}+\boldsymbol{F}_{\boldsymbol{p}}+\boldsymbol{F}_{\text {seat }}-\boldsymbol{W}_{\boldsymbol{c}}-\boldsymbol{k}_{\boldsymbol{c}}\left(\boldsymbol{x}_{\boldsymbol{c}}+\boldsymbol{x}_{\boldsymbol{c} 0}\right)-\boldsymbol{f}_{\boldsymbol{c}} \boldsymbol{x}_{\boldsymbol{c}}^{\prime}
$$

where $\left(m_{c}, x_{c}, W_{c}, k_{c}, f_{c}, x_{c 0}, F_{M}, F_{p}, F_{\text {seat }}\right)$ are the solenoid mass, displacement, weight, spring stiffness, damping coefficient, spring initial compression, and (magnetic, pressure, and seat reaction) forces affecting the solenoid core correspondingly.

$$
\begin{aligned}
\boldsymbol{F}_{p} & =\boldsymbol{P}_{v} \boldsymbol{A}_{s c}=\boldsymbol{P}_{v} * \frac{\pi}{4} d_{s c}^{2} \\
\boldsymbol{F}_{\text {seat }} & = \begin{cases}\mathbf{0} & \boldsymbol{x}_{\boldsymbol{c}}>\mathbf{0} \\
\boldsymbol{k}_{\text {seat }} *\left|\boldsymbol{x}_{\boldsymbol{c}}\right|+\boldsymbol{f}_{\text {seat }} *\left|\boldsymbol{x}_{c}^{\prime}\right| & \boldsymbol{x}_{\boldsymbol{c}} \leq \mathbf{0}\end{cases}
\end{aligned}
$$

where $\left(P_{v}, A_{s c}, k_{\text {seat }}, f_{\text {seat }}\right)$ are the amplifier pressure, solenoid core's area, seat equivalent stiffness, and damping coefficient.

The solenoid used in the present application have been studied before by Metwally [12]. He has deduced the solenoid model into a second order system to estimate solenoid parameters. By using a trial and error approach and a long iteration process he got the solenoid parameters that give the best fit as follows: $\boldsymbol{m}_{\boldsymbol{c}}=\mathbf{0 . 0 2} \mathrm{kg} \quad \boldsymbol{k} c=37500 \mathrm{~N} . \mathrm{m} \quad f c=30 \mathrm{~kg} / \mathrm{s} \quad \boldsymbol{k}_{s i}=\mathbf{5 0}$. 


\subsection{Electro Hydraulic Valve}

In this section the flow equations through the valve, continuity equation, and equation of motion of the spool have been derived.

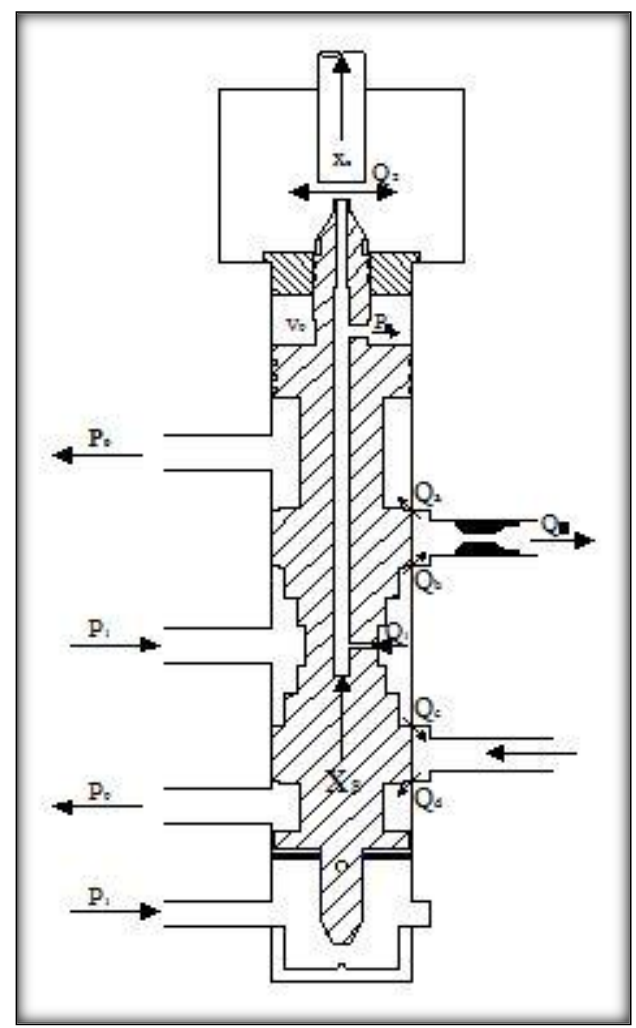

Fig. (4) Hydraulic amplifier

Fuel flow rates through the two restrictions, of the hydraulic amplifier shown in Fig. (4), are given by:

$$
\begin{gathered}
Q_{1}=C_{d} A_{1} \sqrt{\frac{2}{\rho}\left(P_{1}-P_{v}\right)} \\
Q_{2}=C_{d} A_{n} \sqrt{\frac{2}{\rho}\left(P_{v}-P_{0}\right)} \\
A_{1}=\frac{\pi}{4} d_{1}^{2} \quad A_{n}=\pi * g a p \quad \text { gap }=\left(x_{i}+x_{c}-x_{s}\right)
\end{gathered}
$$

where $\left(Q_{1}, A_{1}, Q_{2}, A_{n}, x_{i}, P_{1}, P_{0}, \rho, C_{d}, x_{s}\right)$ are the amplifier inlet port flow rate and area, the amplifier variable nozzle flow rate and area, the initial gap between solenoid and spool, valve supply and return pressures, fuel density, discharge coefficient, and spool displacement.

The continuity equation applied to hydraulic amplifier chamber, neglecting hydraulic losses in amplifier bore, could be written as:

$$
\begin{gathered}
Q_{1}-Q_{2}+A_{s} \frac{d_{s}}{d t}=\frac{V_{0}-A_{s} x_{s}}{B} \frac{d_{P_{v}}}{d t} \\
A_{s}=\frac{\pi}{4}\left(D_{s}^{2}-D_{a}^{2}\right)
\end{gathered}
$$

Where $\left(A_{s}, V_{0}, B\right)$ are valve spool cross sectional area, initial volume, and Bulk's modulus. The motion of the spool is governed by the following equation of motion, neglecting the static friction force:

$$
m_{s} x_{s}^{\prime \prime}=P_{1} A_{r}-P_{v} *\left(A_{s}+A_{2}\right)-f_{s} x_{s}^{\prime}-F_{s s e a t}-F_{j}-W_{s}
$$


The spool displacement is limited mechanically by a limiter at the end of its stroke on both sides. When reaching any of the side limiters the seat reaction develops a counter force, $\mathbf{F}_{\text {sseat }}$, given by equation (13)Error! Reference source not found.

$F_{\text {sseat }}=\left\{\begin{array}{lr}\boldsymbol{k}_{\text {seat }} *\left(x_{s}-x_{\text {smin }}\right)+f_{\text {seat }} * x_{s}^{\prime} & x_{s} \leq x_{\text {smin }} \\ 0 & x_{\text {smin }}<x_{s}<x_{\text {smax }} \\ \boldsymbol{k}_{\text {seat }} *\left(x_{s}-x_{\text {smax }}\right)+f_{\text {seat }} * x_{s}^{\prime} & x_{s} \geq x_{\text {smax }}\end{array}\right.$

As a result of fluid flow, a jet reaction force, $F_{\mathrm{j}}$, equal to the rate of change of the momentum of the fluid is generated [13] equation (14). Also, because of the vertical position of the valve, weight of the spool effects its displacement as described by equation (15).

$$
\begin{aligned}
F_{j} & = \begin{cases}\frac{\rho * Q_{b}^{2}}{C_{c} A_{b}}+\frac{\rho * Q_{d}^{2}}{C_{c} A_{d}} & x_{s}>0 \\
\frac{\rho * Q_{b}^{2}}{C_{c} A_{b}}+\frac{\rho * Q_{d}^{2}}{C_{c} A_{d}} & x_{s}<0\end{cases} \\
W_{s} & =\boldsymbol{m}_{s} g
\end{aligned}
$$

where $\left(m_{s}, A_{r}, A_{2}, f_{s}, F_{j}, F_{s s e a t}, W_{s}, x_{\text {smin }}, x_{\text {smax }}, c_{c}\right)$ are the spool's mass, the rear cap and nozzle bore areas, the spool damping coefficient, the jet reaction and the seat reaction forces, the spool's weight, the spool's minimum and maximum displacement limits, and the contraction coefficient.

where $\left(Q_{a}, Q_{b}, Q_{c}, Q_{d}, A_{a}, A_{b}, A_{c}, A_{d}\right)$ are ports openings (a, b, c \& d) flow rates and areas.

Neglecting the losses through the transmission lines, which connect the valve to the actuator, the flow rates through the valve restriction areas are given by:

$$
\begin{aligned}
Q_{a} & =C_{d} A_{a} \sqrt{\frac{2}{\rho}\left(P_{x}-P_{0}\right)} \\
Q_{b} & =C_{d} A_{b} \sqrt{\frac{2}{\rho}\left(P_{1}-P_{x}\right)} \\
Q_{c} & =C_{d} A_{c} \sqrt{\frac{2}{\rho}\left(P_{1}-P_{B}\right)} \\
Q_{d} & =C_{d} A_{d} \sqrt{\frac{2}{\rho}\left(P_{B}-P_{0}\right)} \\
Q_{t h} & =C_{d} A_{t h} \sqrt{\frac{2}{\rho}\left(P_{x}-P_{A}\right)}
\end{aligned}
$$

The valve restriction areas can be classified into radial clearance area and port opening area. The radial clearance area is calculated in equation (21). The port opening area, as illustrated in Fig. (5), can be described by equations (22) \& (23).

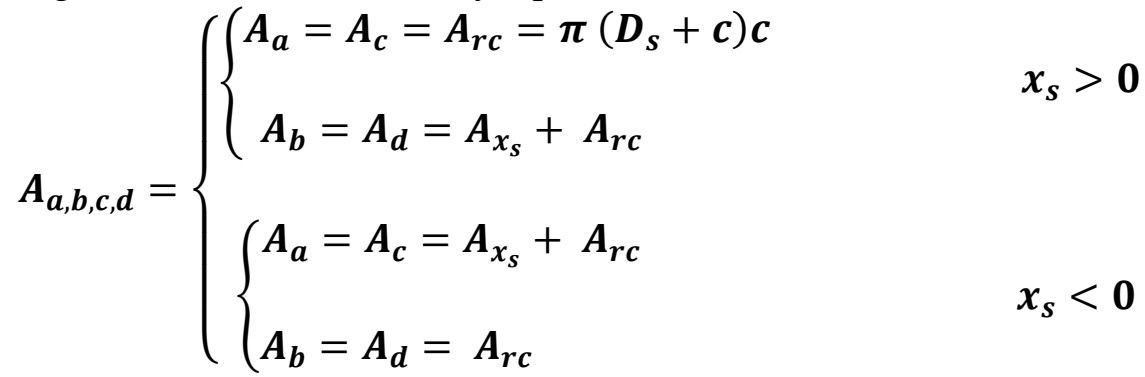

$$
\begin{aligned}
& A_{x_{s}}=\left.4 * A_{x_{s}}\right|_{p} \\
& \left.A_{x_{s}}\right|_{p}=r_{p}^{2} * \cos ^{-1}\left(\frac{r_{p}-\left|x_{s}\right|}{r_{p}}\right)-\left(r_{p}-\left|x_{s}\right|\right) * \sqrt{2 * r_{p} *\left|x_{s}\right|-x_{s}^{2}} \\
& \boldsymbol{A}_{\mathrm{th}}=\frac{\pi}{4} \boldsymbol{d}_{\text {th }}^{2}
\end{aligned}
$$

where $\left(P_{x}, P_{A}, P_{B}, r_{p}, A_{t h}, A_{r c}, A_{x s},\left.A_{x s}\right|_{p}\right)$ are the throttle, cap side and rod side pressures and the port radius, the throttle orifice and radial clearance areas, the area of all ports opening, and the area of single port opening. 
By applying the continuity equation on the valve outlet neglecting the external leakage, equations (25) \& (26) were obtained.

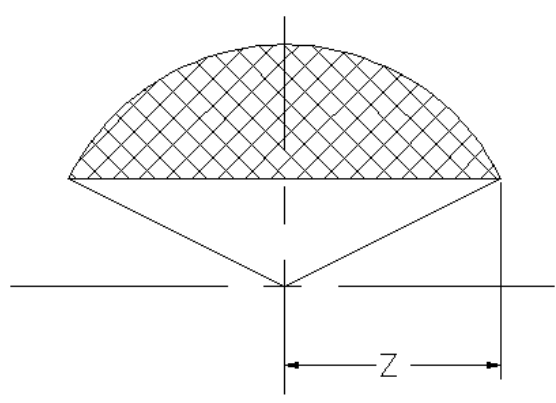

Sector Area

Triangle Area

Segment Area

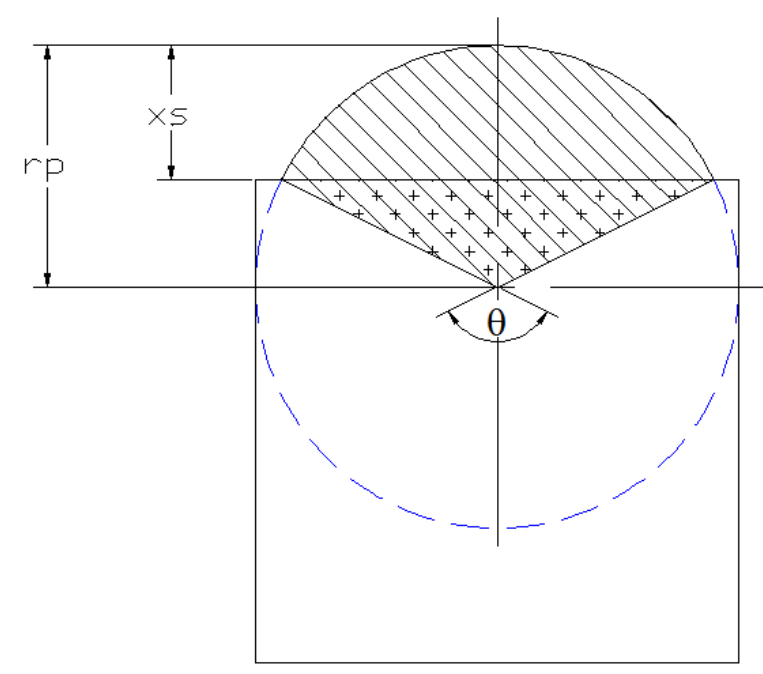

Fig. (5) Description of valve's port opening area calculation

$$
\begin{gathered}
Q_{b}-Q_{a}-Q_{\text {th }}=\frac{V_{x}}{B} \frac{d P_{x}}{d t} \\
Q_{c}-Q_{d}+Q_{B}=0
\end{gathered}
$$

where $\left(V_{x}, Q_{B}\right)$ are the throttle volume and flow rate at valve outlet on the actuator's rod side.

\subsection{Electro Hydraulic Servo Actuator}

The electrohydraulic valve controls the piston's movement both its direction and rate, in order to maintain accurate position control. To study the piston response to the fuel flow rate delivered by the valve, the continuity equation of the actuator as well as the equation of motion of the piston was discussed as follows.

Applying the continuity equation to the cylinder chamber considering the internal leakage and neglecting the external leakage, equations $(27,28,29$ were obtained.

$$
\begin{aligned}
& A_{\mathrm{B}} \frac{\mathrm{dY}}{\mathrm{dt}}+\frac{P_{A}-P_{B}}{R_{i}}-\mathbf{Q}_{\mathrm{B}}=\frac{\mathrm{V}_{\mathrm{B}}-\mathrm{A}_{\mathrm{B}} * \mathrm{Y}}{\mathrm{B}} \frac{\mathrm{dP}_{\mathrm{B}}}{\mathrm{dt}} \\
& \mathbf{Q}_{\mathrm{th}}-\mathbf{A}_{\mathrm{A}} \frac{\mathrm{dY}}{\mathrm{dt}}-\frac{P_{A}-P_{B}}{R_{i}}=\frac{\mathrm{V}_{\mathrm{A}}-\mathrm{A}_{\mathrm{A}} * \mathrm{Y}}{\mathrm{B}} \frac{\mathrm{dP}_{\mathrm{A}}}{\mathrm{dt}} \\
& A_{A}=\frac{\pi}{4} * D_{A}^{2} \quad A_{B}=\frac{\pi}{4}\left(D_{A}^{2}-D_{B}^{2}\right)
\end{aligned}
$$

where ( $\left.V_{A}, V_{B}, A_{A}, A_{B}, R_{i}, \mathrm{Y}\right)$ are the actuator's cap and rod side initial volumes, the piston's cap and rod side areas, the internal leakage resistance and the actuator's displacement.

The motion of the piston under the action of pressure difference, viscous friction, inertia, external forces, and its own weight was described by equation (30). In addition, the seat reaction force, due to mechanical limitation, was taken into consideration equation (31).

$$
\begin{aligned}
& \boldsymbol{m}_{\boldsymbol{p}} \boldsymbol{Y}^{\prime \prime}=\boldsymbol{P}_{\boldsymbol{A}} \boldsymbol{A}_{\boldsymbol{A}}-\boldsymbol{P}_{\boldsymbol{B}} \boldsymbol{A}_{\boldsymbol{B}}-\boldsymbol{f}_{\boldsymbol{p}} \boldsymbol{Y}^{\prime}-\boldsymbol{F}_{\text {Aseat }}-\boldsymbol{F}_{\text {load }}+\boldsymbol{W}_{\boldsymbol{p}} \\
& \boldsymbol{F}_{\text {Aseat }}=\left\{\begin{array}{lr}
\boldsymbol{k}_{\text {seat }} * \boldsymbol{Y}+\boldsymbol{f}_{\text {seat }} * \boldsymbol{Y}^{\prime} & \boldsymbol{Y} \leq \mathbf{0} \\
\mathbf{0} & \boldsymbol{Y}<\boldsymbol{Y}_{\text {max }} \\
\boldsymbol{k}_{\text {seat }} *\left(\boldsymbol{Y}-\boldsymbol{Y}_{\text {max }}\right)+\boldsymbol{f}_{\text {seat }} * \boldsymbol{Y}^{\prime} & \boldsymbol{Y} \geq \boldsymbol{Y}_{\text {max }}
\end{array}\right. \\
& \boldsymbol{W}_{\boldsymbol{p}}=\boldsymbol{m}_{\boldsymbol{p}} * \boldsymbol{g}
\end{aligned}
$$


where $\left(f_{p}, F_{\text {Aseat }}, F_{\text {load }}, m_{p}, W_{p}, Y_{\max }\right)$ are the actuator's damping coefficient, seat reaction and load forces, the piston's mass, weight and stroke.

The short tube orifice Fig. (2) has a nonlinear discharge coefficient, equation (20), depends on Reynolds's number [13], which in turn depends on fluid speed, which is very hard to be measured. In this case, the orifice was treated as a sharp edge orifice with discharge coefficient of (0.6) then the whole model solved using SIMULINK for a different step inputs.

\section{Experimental Work}

In order to measure the system response a test rig has been built, as shown in figure. The test rig consists of a bench with fuel tank, fuel water separator, two filtering units, and the main fuel consol. The pump, the electrohydraulic valve and the RVDT contained in the main fuel consol. The system is driven by an $\mathrm{AC}$ motor with invertor to control the motor speed. An electronic circuit was designed to help expedite measuring and controlling the system. The measurements were made using a DAQ (NI PCIe/PXIe-6363) and an interface program designed for this purpose on LabVIEW.

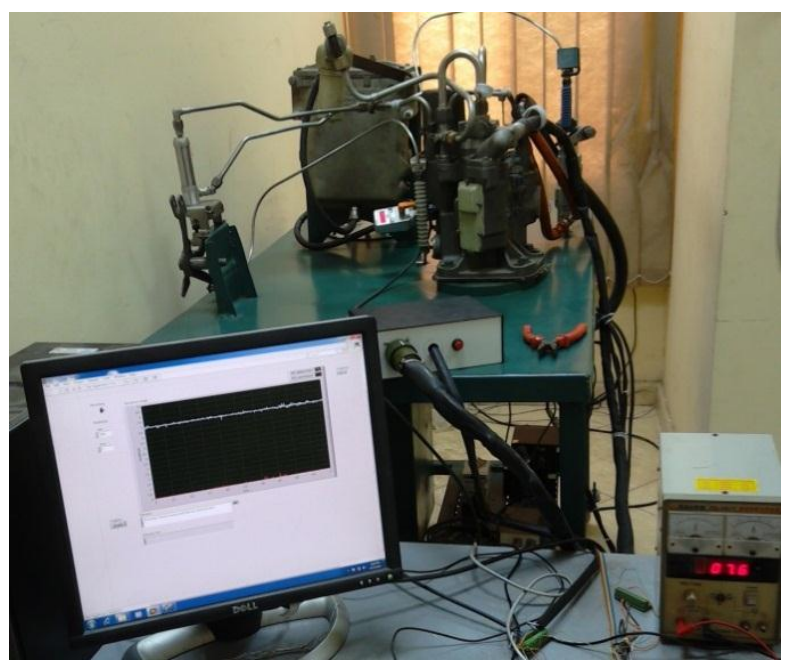

The system response for different step inputs was measured and compared with the predicted one as shown in Fig. (6). The left graph represents the actuator displacement to a step input of 7 volts, while the right one represents the displacement responded to step input of $8 \mathrm{~V}$. the $\mathrm{x}-$ axis in both graphs represents time in (seconds). The left y-axis in each graph represents actuator displacement in $(\mathrm{mm})$, while the right $\mathrm{y}$-axis in each graph represents solenoid step input in (volts).

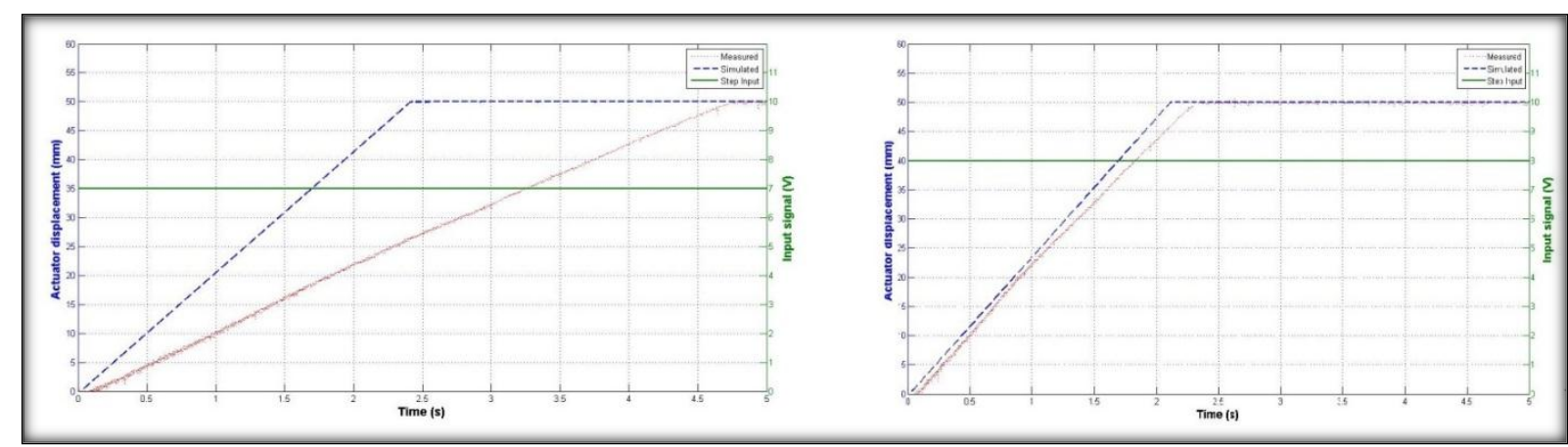

Fig (6) Comparing predicted and measured response for different step inputs

The illustrated response in Fig (6) shows that the predicted results are close to the measured results for some step inputs and too far for others.

In order to correct the assumption of short tube discharge coefficient, the average velocity of the piston has to be studied. Figure (7) shows a comparison between experimental and predicted average velocity of the piston. The experimental and predicted velocity carves are not similar, but approximately met at step inputs $8.5 \mathrm{~V}$ and $2.5 \mathrm{~V}$ which are $3 \mathrm{~V}$ away from the null input $(5.5 \mathrm{~V})$. The extension response (above $5.5 \mathrm{~V}$ ) is faster than the retraction response (less $5.5 \mathrm{~V}$ ) 
in both measured and predicted results because of the effect of piston weight and different piston areas proposed to the fluid pressure. A variable discharge coefficient values for short tube orifice has been estimated in both the extension and the retraction directions of the piston's movement iteratively. Figure (8) shows the estimated discharge coefficient values on y-axes (dimensionless) against absolute spool position on $\mathrm{x}$-axes $(\mathrm{mm})$ for both piston's movement directions, extension (doted) and retraction (dashed).

The estimated discharge coefficient values were integrated into the mathematical model in SIMULINK and solved again for different step inputs. The resultant predicted behavior of the system and its comparison with the measurements is depicted in the following figures.

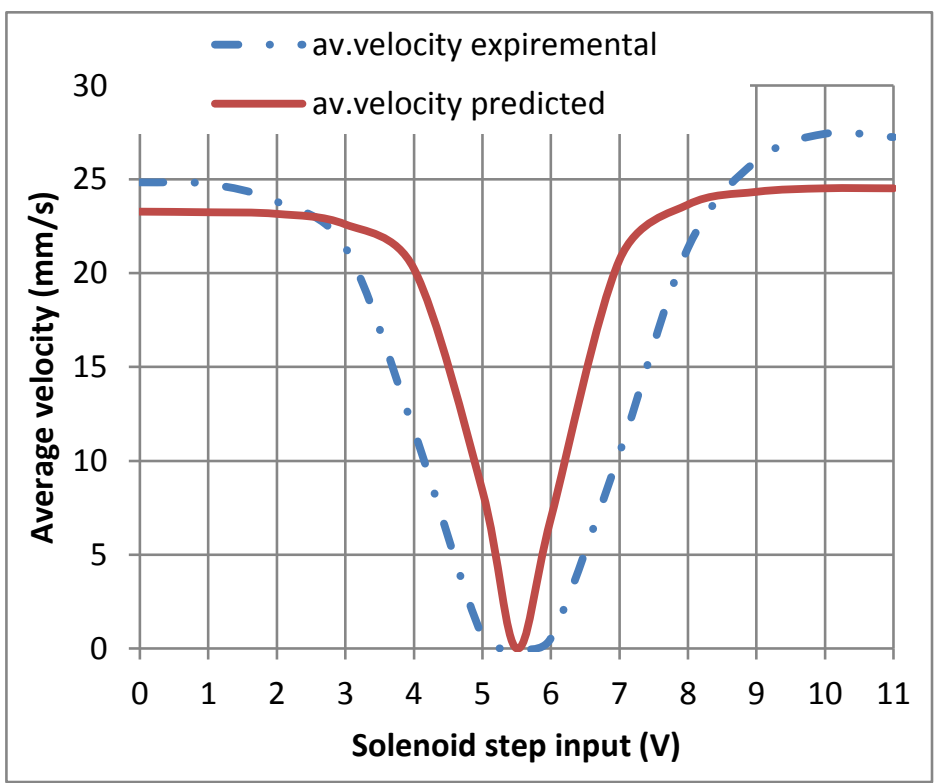

Fig (7) Comparing experimental and predicted average velocity for the same step inputs

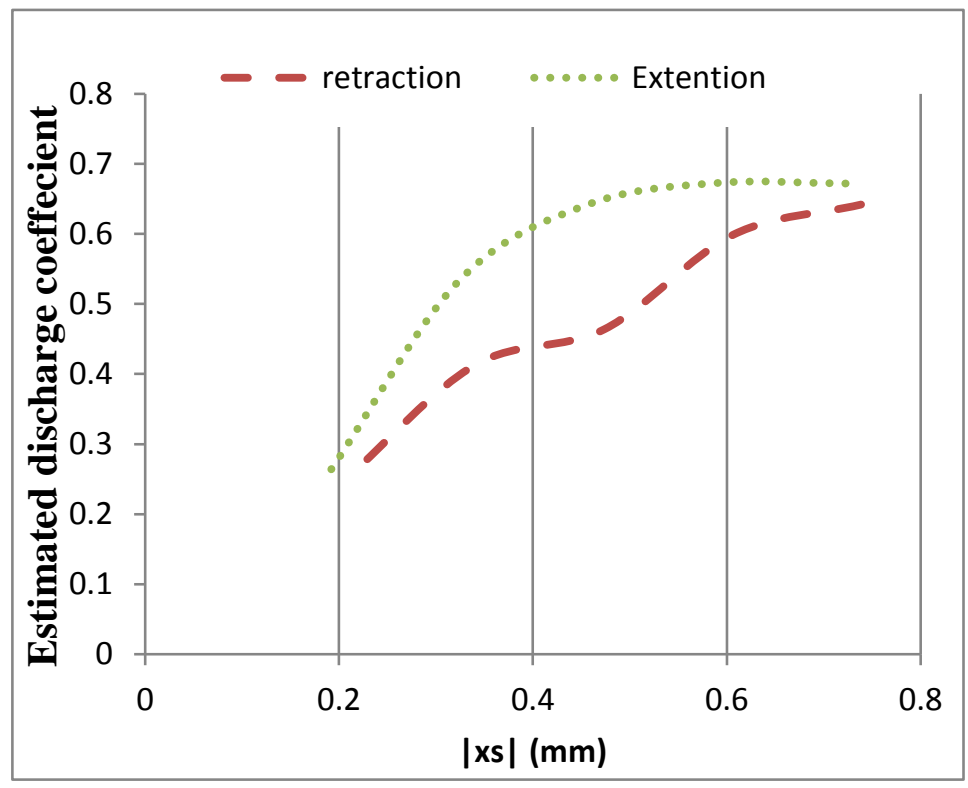

Fig (8) Estimated discharge coefficients for short tube orifice in both extension and retraction directions 


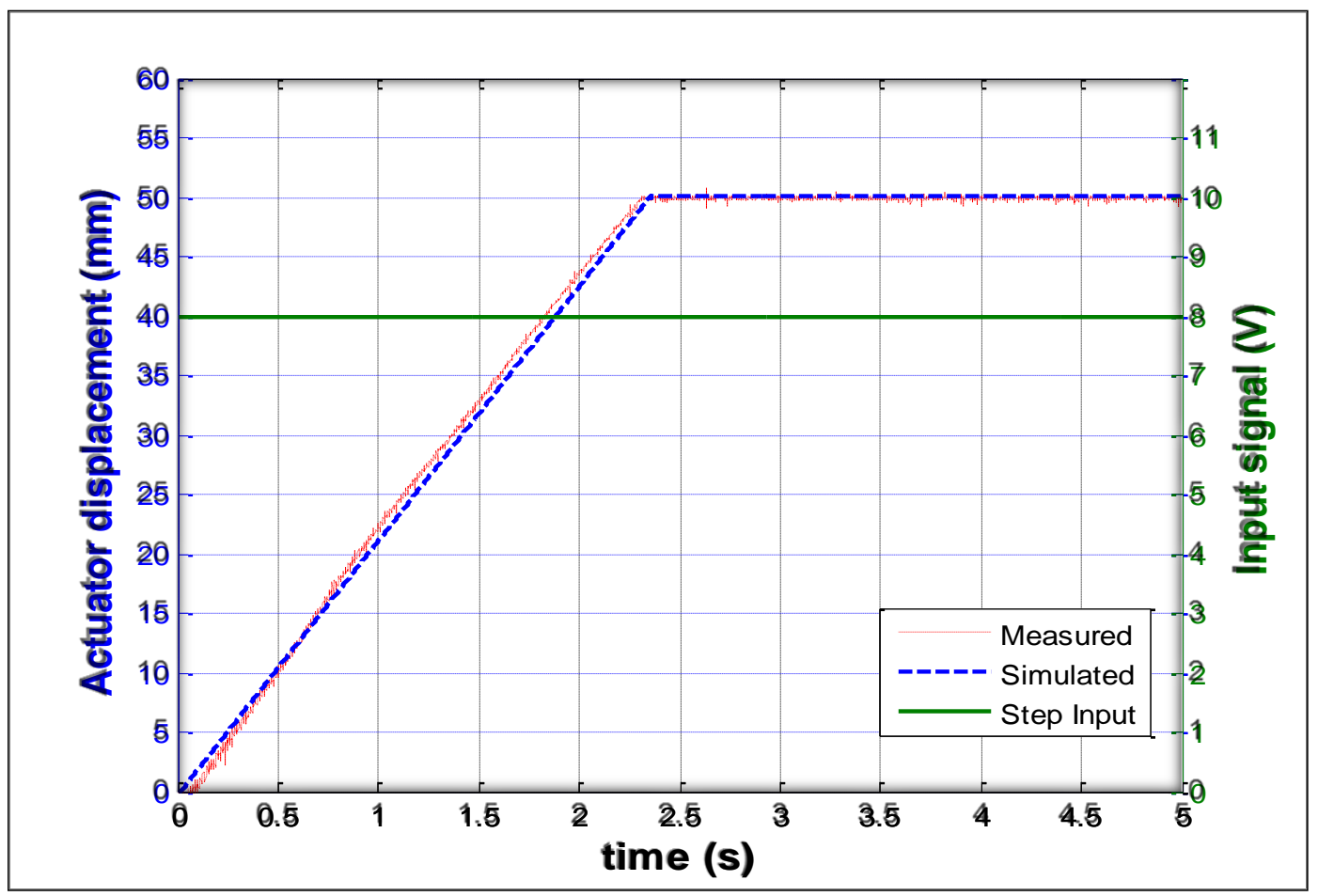

Fig (9) Measured vs. Simulated response to (8V) stepinput (piston extention)

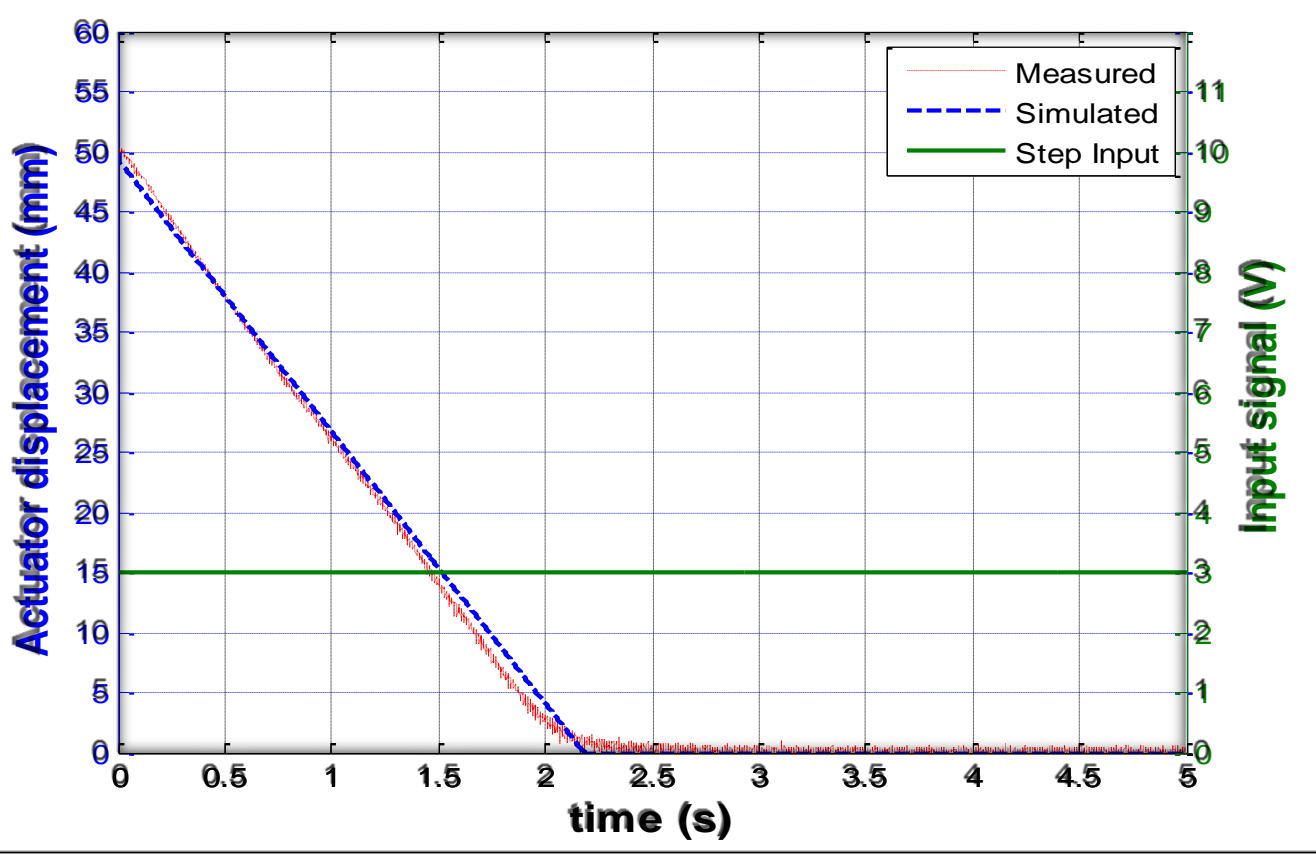

Fig (10) Measured vs. Simulated response to (3V) stepinput (piston retraction)

Figures (9) and (10) show a comparison between experimental and predicted system response for step inputs of $8 \& 3$ volts respectively. The $\mathrm{x}$-axis in both graphs represents time in (seconds). The left y-axis in both graphs represents actuator displacement in (mm), while the right y-axis in each graph represents solenoid step input in (volts). Figure (9) compares the experimental and the predicted actuator's displacement in extension direction of the piston while Fig. (10) compares the same for piston's retraction. The results show good match between experimental and predicted behavior of the system. The maximum difference between predicted and measured displacement is less than $3 \%$ of the full stroke. 


\section{Conclusion}

Accordingly, the mathematical dynamic model represented in this paper and it's simulation on SIMULINK can be considered as a validated model for the described system. Furthermore, it can be used to design and compare the effect of different control techniques on the system behavior for further development.

\section{References}

[1] Y. Yang, S. N. Balakrishnan, L. Tang, and R. G. Landers, "Electro-Hydraulic Piston Control using Neural MRAC Based on a Modified State Observer," 2011.

[2] B. Yu, Y. Shi, and J. Huang, "Modified Generalized Predictive Control of Networked Systems With Application to a Hydraulic Position Control System," Journal of Dynamic Systems, Measurement, and Control, vol. 133, p. 031009, 2011.

[3] A. Sadeghieh, H. Sazgar, K. Goodarzi, and C. Lucas, "Identification and real-time position control of a servo-hydraulic rotary actuator by means of a neurobiologically motivated algorithm," ISA Trans, vol. 51, pp. 208-19, Jan 2012.

[4] W. Acunña-Bravo, Y. Ma, and E. Canuto, "Position control of proportional electrohydraulic valves: An Embedded Model Control solution," in Control Conference (CCC), 2015 34th Chinese, 2015, pp. 8647-8652.

[5] W. Y. Lai, N. Onn, C. H. H. Tang, and M. Hussein, "Position Control of Hydraulic Actuators Using Fuzzy Pulse Width Modulation (PWM)," Applied Mechanics and Materials, vol. 735, pp. 294-298, 2015.

[6] Y. Ye, C.-B. Yin, Y. Gong, and J.-j. Zhou, "Position control of nonlinear hydraulic system using an improved PSO based PID controller," Mechanical Systems and Signal Processing, vol. 83, pp. 241-259, 2017.

[7] N. C. Cheung, K. W. Lim, and M. F. Rahman, "Modelling a linear and limited travel solenoid," in Industrial Electronics, Control, and Instrumentation, 1993. Proceedings of the IECON \&\#039;93., International Conference on, 1993, pp. 1567-1572 vol.3.

[8] N. D. Vaughan and J. B. Gamble, "The Modeling and Simulation of a Proportional Solenoid Valve," Journal of Dynamic Systems, Measurement, and Control, vol. 118, p. 120, // 1996.

[9] Y.-f. Liu, Z.-k. Dai, X.-y. Xu, and L. Tian, "Multi-domain modeling and simulation of proportional solenoid valve," Journal of Central South University of Technology, vol. 18, pp. 1589-1594, 10/01/2011.

[10] J. Yan, B. Li, H.-F. Ling, H.-S. Chen, and M.-J. Zhang, "Nonlinear State Space Modeling and System Identification for Electrohydraulic Control," Mathematical Problems in Engineering, vol. 2013, pp. 1-9, 2013.

[11] T. Puller and A. Lecchini-Visintini, "Modelling for control of a jet engine compressor variable stator vanes hydraulic actuator," presented at the 2016 European Control Conference (ECC) June 29 - July 1, 2016. Aalborg, Denmark, 2016.

[12] M. Metwally, "Investigation of Fluid Power System Controller at Start/Stop Conditions (Gas Turbine Engine)," PhD, MTC, Cairo, 2007.

[13] M. G. Rabie, Fluid_Power_Engineering: McGraw-Hill, 2009. 